\title{
Identification of New QTL Contributing to Barley Yellow Dwarf Virus-PAV (BYDV-PAV) Resistance in Wheat
}

\author{
S. Choudhury, ${ }^{1}$ H. Hu, ${ }^{1}$ Y. Fan, ${ }^{1}$ P. Larkin, ${ }^{2}$ M. Hayden, ${ }^{3}$ K. Forrest, ${ }^{3}$ C. Birchall, ${ }^{4}$ H. Meinke, ${ }^{1}$ R. Xu, ${ }^{5}$ J. Zhu, ${ }^{1,5}$ \\ and M. Zhou ${ }^{1, \dagger}$ \\ ${ }^{1}$ Tasmanian Institute of Agriculture, University of Tasmania, Prospect, TAS 7250, Australia \\ ${ }^{2}$ CSIRO Agriculture and Food, Canberra, ACT 2601, Australia \\ ${ }^{3}$ Agriculture Victoria Research, AgriBio, Bundoora, Victoria 3083 Australia \\ ${ }^{4}$ School of Environmental and Rural Science, University of New England, Armidale NSW 2351, Australia \\ ${ }^{5}$ Barley Research Institution of Yangzhou University, Yangzhou University, Yangzhou, 225009, China
}

\begin{abstract}
Barley yellow dwarf (BYD) is a major virus disease which dramatically reduces wheat yield. Introducing BYD resistance genes into commercial varieties has been proven to be effective in reducing damage caused by barley yellow dwarf virus (BYDV). However, only one major resistance gene is readily deployable for breeding; $B d v 2$ derived from Thinopyrum intermedium is deployed as a chromosomal translocation. In this study, a double haploid (DH) population was developed from a cross between XuBYDV

of DH lines inoculated with BYDV was assessed at the heading stage. The infections were assessed by tissue blot immunoassay (TBIA). Three new QTL were identified on chromosomes 5A, 6A, and 7A for both symptom and TBIA, with all three resistance alleles being inherited from XuBYDV. Some DH lines with the resistance alleles from all three QTL showed high level resistance to BYD. These new QTL will be useful in breeding programs for pyramiding BYD resistance genes.
\end{abstract} (introduced from China showing very good resistance to BYD) and $\mathrm{H}-$ 120 (a BYD-sensitive Chinese accession), and was used to identify QTL for BYD resistance. The population was genotyped using an Infinium iSelect bead chip array targeting $90 \mathrm{~K}$ gene-based SNPs. The disease resistance
Keywords: wheat, barley yellow dwarf virus, quantitative trait loci, symptom score, resistance gene, viruses and viroids, field crops, disease management, cultivar/resistance
Barley yellow dwarf virus (BYDV) has been identified as one of the most destructive viral diseases of cereal crops (JimenezMartinez and Bosque-Pérez 2004), adversely affecting wheat production and causing important economic losses all over the world (Huth 2000). BYDV is phloem limited and belongs to the Luteoviridae family with some virus species being assigned to the genus Luteovirus (BYDV-PAV, BYDV-PAS, BYDV-MAV). BYDV has a wide host range and is not mechanically or seed transmitted. The virus can only be transmitted in a persistent manner and by more than 25 aphid species (Halbert and Voegtlin 1995). BYDV-PAV is the most common virus serotype (Griesbach et al. 1990), transmitted specifically by the aphids Rhopalosiphum padi and Schizaphis graminum (Kaddachi et al. 2014; Miller and Rasochová 1997). In host plants, virus transmission occurs when aphid feeds on the phloem sieve tube elements (Hewer et al. 2011). Compared with uninfected plants, BYDV-infected plants appear stunted and chlorotic (Hoffman and Kolb 1997). Unlike acute injury caused by cereal aphids, from which the plant can recover if the aphids are removed (Riedell et al. 2003), the injury in cereal plants caused by BYDV infection is chronic and plants are unable to recover from the infection. BYDV infection which occurs before tillering can decrease grain yield in

${ }^{\dagger}$ Corresponding author: M. Zhou; Meixue.zhou@utas.edu.au

Funding: This work was supported by the Grains Research and Development Corporation (GRDC) of Australia (UT00030), and National Key R\&D Program of China (2017YFD0100800).

*The $\boldsymbol{e}$-Xtra logo stands for "electronic extra" and indicates that three supplementary figures and two supplementary tables are published online.

The author(s) declare no conflict of interest.

Accepted for publication 28 May 2019.

(C) 2019 The American Phytopathological Society wheat by 9 to $79 \%$ (Smith and Sward 1982); thus, early control of aphids is crucial to reduce the virus impact.

While early control of aphids can be very effective for reducing virus infection, the use of insecticides to prevent aphids can be costly because each arrival of viruliferous aphids must be anticipated and mitigated swiftly. The best, long-term, and environmentally safe method for sustainable virus control is the use of resistant genotypes (Ordon et al. 2004). Useful plant genetic controls for BYD can be classified as tolerance (although virus multiplication is not changed, symptoms and yield losses are reduced) or resistance (virus multiplication and symptoms are restricted or prevented in a host species) (Cooper and Jones 1983). The use of resistant germplasm is still one of the most promising methods for controlling BYD disease.

The use of natural infections in the field, with typically uneven distribution of aphids, is a problem for effective breeding progress. Consequently, artificial inoculation is required for reliable selection of BYD resistant genotypes (Comeau 1992). Artificial inoculation can assist the transmission of a precise isolate to plants at a determined and uniform developmental stage (Baltenberger et al. 1987). Leaf symptoms commonly found in BYDV-infected plants are often used to select plants for BYD resistance, in particular wheat, barley, and oat (Choudhury et al. 2018; Kosova et al. 2008; Veškrna et al. 2009). However, for the diagnosis of BYDV infection, visual symptoms are sometimes not sufficient, since the symptoms might be confused with other biotic and abiotic stresses. Thus, laboratory techniques have been developed to overcome the unreliable visual symptoms. BYD resistant genotypes can be identified by low virus concentrations. In Poaceae plants, 13 different types of viruses were successfully identified by tissue blot immunoassay (TBIA) (Huth 1999). TBIA is reported to be more reliable for detecting phloem-limited viruses, even at low concentration, and is therefore well suited for identifying BYD resistant genotypes (Makkouk and Comeau 1994).

The evaluation of wheat for BYD resistance using aphid inoculation and laboratory analyses can be laborious and costly. Marker assisted selection (MAS) for identified genes allows for quicker progress in breeding wheat for BYD resistance (Kearsey and Farquhar 1998). BYD tolerance is reported to be polygenic in wheat (Cisar et al. 1982; 
Tola and Kronstad 1984), barley (Qualset 1992; Schaller 1984), and oats (McKenzie et al. 1985). Genomic regions involved in tolerance to BYD have been mapped in oats (Barbosa-Neto et al. 2000; Jin et al. 1998) and barley (Toojinda et al. 2000). No effective BYD resistance gene has been found in bread wheat (Ayala et al. 2001), although partial tolerance conferred by $B d v 1$ has been located on 7DS (Ayala et al. 2002; Singh et al. 1993). The first BYD resistance gene successfully used in wheat breeding was $B d v 2$, which originated from an intermediate wheatgrass Thinopyrum intermedium and was introduced into wheat as an alien chromosomal translocation (Choudhury et al. 2018; Stoutjesdijk et al. 2001). $B d v 2$ does not provide complete resistance, and its effects on grain yield (Zhou et al. 2015) and quality are under evaluation, adding to the need to find new sources of resistance so breeders can pyramid different genes to make plants more resistant to BYDV infection. In the present study, a doubled haploid (DH) population was used to identify QTL controlling resistance to BYD. TBIA scores and symptom severity of those DH lines after viruliferous aphid inoculation were used as the indicators for BYD resistance.

\section{Materials and Methods}

Plant material and inoculation. A doubled haploid (DH) population consisting of $180 \mathrm{DH}$ lines was constructed from $\mathrm{F}_{1}$ plants of the wheat cross between XuBYDV (BYD resistant) and H-120 (BYD susceptible) at the Department of Agriculture and Food WA, Australia. Both XuBYDV, a breeding line, and H-120 (Bima 4, an old variety with a pedigree of Mazamai $\times$ Biyumai) are genotypes introduced from China. All $\mathrm{DH}$ lines and parents were grown in small pots containing 2:1 ratio of potting mix and sand. At the 2-leaf stage, each plant was inoculated with 5 to 10 viruliferous aphids for 4 days. At the end of the feeding period, aphids were sprayed with insecticide lambda-cyhalothrin (Karate; Syngenta). Two weeks after inoculation, the plants were transplanted into the field and grown to maturity using standard agronomic management practices. Trials were conducted at the Tasmanian Institute of Agriculture, Launceston, Australia, in the 2016-17 and 2017-18 growing seasons. Each trial had two replications with each replicate having five plants.

Aphid colony and virus isolate. Colonies of adult bird cherry oat aphid, Rhopalosiphum padi, were collected from the field, and newly laid juveniles were transferred to uninfected plants grown in small cages before they were fed with BYDV-infected plants. The populations were then raised on oats (cv. Eurabbie) in small cages at $20^{\circ} \mathrm{C} \pm 2{ }^{\circ} \mathrm{C}, 65 \pm 5 \%$ $\mathrm{RH}$, with a photoperiod of L14:D10 using cool-white fluorescent light under $450 \mu \mathrm{mol}-\mathrm{m}^{-2} \mathrm{~s}^{-1}$ photosynthetically active radiation.

The BYDV-PAV isolate was collected from a wheat field in northern New South Wales (Australia) in 2010 and maintained in oat plants (Eurabbie) in an aphid-free glasshouse at the University of New England, Armidale, Australia with groups of tillers being vegetatively propagated as required to maintain active plant growth under the same conditions as the aphid colonies. The virus isolates were periodically (8-weekly) transferred to new plants (a sensitive wheat genotype Revenue) using $R$. padi. Infection of the plants was confirmed by regular ELISA testing of the leaves.

Reverse transcription-PCR analysis. XuBYDV and H-120 were inoculated with 5 to 10 viruliferous aphids for 4 days. Leaf samples were taken after 10 days infection. Control plants were sprayed for aphids. The detection of the infection of luteovirus families (BYDVPAV/RMV and CYDV-RPV) by qPCR followed the procedure described by Nagy et al. (2007) and Balaji et al. (2003). The 18S rRNA primers were used as an endogenous internal control (Supplementary Table S1). Differences between the $\mathrm{Ct}$ values of target gene and $18 \mathrm{~S}$ rRNA were calculated as $\Delta \mathrm{Ct}=\mathrm{Ct}$ target gene $-\mathrm{Ct} 18 \mathrm{~S}$ rRNA, and the relative expression levels of the target gene were determined as $2^{-\Delta C t}$. For each sample, PCR was performed with three biological replicates. The average values of $2^{-\Delta \mathrm{Ct}}$ were used to determine difference in gene expression. Semiquantitative PCR was performed by using a PCR machine (Eppendorf, Germany), programmed for an initial $3 \mathrm{~min}$ denature at $94^{\circ} \mathrm{C}$, followed by 26 cycles for $30 \mathrm{~s}$ at $94^{\circ} \mathrm{C}, 30 \mathrm{~s}$ at $55^{\circ} \mathrm{C}, 30 \mathrm{~min}$ at $72^{\circ} \mathrm{C}$, and a final $5 \mathrm{~min}$ at $72^{\circ} \mathrm{C}$. Amplification products were separated by $1 \%$ agarose gels.

Sequencing of BYDV-PAV. Four primers (Supplementary Table S2) were designed according to the GenBank X07653 (5,677 bp) to amplify using $200 \mathrm{ng}$ template RNA extracted from infected wheat leaf plants. The PCR conditions were: an initial 5 min denature at $94^{\circ} \mathrm{C}$, followed by 32 cycles for $30 \mathrm{~s}$ at $94^{\circ} \mathrm{C}, 50 \mathrm{~s}$ at $55^{\circ} \mathrm{C}, 2 \mathrm{~min}$ at $72^{\circ} \mathrm{C}$, and a final $10 \mathrm{~min}$ at $72^{\circ} \mathrm{C}$. Amplification products were separated by $1 \%$ agarose gels and selected fragments were purified via a TAKARA Midi Purification Kit (TAKARA, Japan). All sequencing reactions were carried out at the Australian Genome Research Facility (Melbourne, Australia).

Evaluation of BYDV infection. At heading stage, three tillers from each hill were assessed according to the procedure outlined in Schwinghamer et al. (2014). Each tiller was blotted onto nitrocellulose membranes, bioassayed with polyclonal (BYDV-PAV/MAV) or monoclonal (BYDV-PAV) antisera (Agdia, Elkhart, IN, U.S.A.). The TBIA procedure of Lin et al. (1990) was modified as follows: Tris-buffered saline (TBS) (0.02 M Tris-HCl, pH 7.5, $0.15 \mathrm{M} \mathrm{NaCl})$ was used rather than phosphate buffered saline as basic buffer for antibody dilution and membrane washing; $1 \mu \mathrm{g} / \mathrm{ml}$ polyvinyl alcohol (Sigma MW 30,000-70,000) was used as preincubation blocking agent; $2 \%$ polyvinyl pyrrolidone (Sigma PVP-40) and $0.2 \%$ egg albumin were added to basic buffer for dilution and incubation of monoclonal antibodies and alkaline phosphatase conjugated antibodies. For TBIAs that used polyclonals as primary antibodies, binding to host antigens was eliminated by dilution and preincubation at $37^{\circ} \mathrm{C}$ for $2 \mathrm{~h}$ in strained leaf extract $(1 \mathrm{~g}$ leaf per $50 \mathrm{ml}$ TBS$)$ of uninfected wheat, before adding the antibody mixture to membranes. The infection was visually assessed in a dissecting microscope. The severity of BYDV infection tested by TBIA was scored on a 0-3 scale (Supplementary Fig. S1). The scores considered the number of vascular bundles infected by virus. Score 0 represented no virus; score 0.5 represented very low level virus, number of vascular bundles $(<10 \%)$ infected, very low staining vascular bundle; score 1 represented low number of vascular bundles ( $>10$ to $25 \%$ ) infected, low staining of vascular bundle; score 2 represented moderate number of vascular bundles ( $>25$ to $50 \%$ ) infected, moderate staining of vascular bundle; and score 3 represented higher number of vascular bundles $(>50 \%)$ infected, strongly stained vascular bundles.

Disease symptoms of BYDV-infected plants were visually assessed at heading stage. The severity of symptom development was scored on a $0-5$ scale, which assessed the proportion of leaves showing red to yellow discoloration in the inoculated plants. $0=$ no symptoms; 1 = plants have a few $(<20 \%)$ discolored leaves; 2 , 3,4 , and 5 represent approximately 20, 40,60\%, and almost all $(>60 \%)$ of leaves affected (Supplementary Fig. S2).

DNA genotyping. DNA was extracted from leaf tissue collected at the 2-leaf seedling stage for each DH and parental line. Genotyping was performed using the Illumina iSelect 90,000 SNP bead chip assay as described in Wang et al. (2014). Missing genotypes were imputed using LinkImpute (Money et al. 2015), with default parameters.

Genetic map construction and QTL analysis. The software package Join Map v4.0 was used to construct the linkage map (Ooijen and Kyazma 2009). The software package Map QTL v6.0 was used to detect QTL (Ooijen and Kyazma 2009) that were firstly analyzed by interval mapping (IM). The closest marker at each QTL identified by IM was selected as a cofactor in the multiple QTL model (MQM). The logarithm of the odds (LOD) threshold value of 3.0 was used to declare the presence of a QTL. The variance percentage explained for each QTL $\left(\mathrm{R}^{2}\right)$ was obtained by restricted MQM mapping. Linkage maps showing the QTL positions were made using MAPCHART (Voorrips 2002). The sequences of flanking SNP markers were used to locate the QTL position on the wheat physical map and searching for candidate genes.

Statistical analysis. Heritability was estimated from ANOVA using the formula: $h^{2}=\sigma^{2}{ }_{G} /\left[\sigma^{2}{ }_{G}+\left(\sigma^{2} e / r\right)\right]$, with $\sigma^{2}{ }_{G}$ the genetic variance, $\sigma^{2}{ }_{e}$ the residual variance, and $r$ the number of replicates per genotype (Nyquist and Baker 1991).

\section{Results}

RT-PCR of BYDV-PAV/RMV and CYDV-RPV and sequencing of BYDV-PAV. qPCR and semiquantitative PCR showed that 
both BYDV-RMV and CYDV-RPV were not detected in both parents (Supplementary Fig. S3). A high concentration of BYDVPAV was only detected in a susceptible host. The complete genomic RNA of the PAV isolate of BYDV was sequenced, and 5,674 nucleotides of the genome were determined. The nucleotide sequence comparative analysis showed $96.64 \%$ sequence similarity with the Australia isolate (GenBank: X07653.1) (Miller et al. 1988). Sequencing of the virus was submitted to The National Center for Biotechnology Information (NCBI) with Genebank accession of MK962883.

Map construction. The $\mathrm{DH}$ lines and the two parental varieties were genotyped using 90,000 gene-based SNP markers that are evenly distributed over the whole genome. A total of 10,450 SNP markers revealed polymorphism between XuBYDV and H-120 and segregated among the DH lines. After removing redundant (i.e., cosegregating) markers, a total of 3,138 markers were used for genetic linkage map construction.

BYD symptom severity of the DH population. The average symptom score for XuBYDV (1.0) was significantly lower than that of H-120 (3.0-3.5) (Table 1). The scores of DH lines showed a normal distribution (Fig. 1A) with transgressive segregation for both trials (2016 and 2017), ranging from 0 (very resistant) to 5.0 (very susceptible). The 2016 trial produced a lower average BYD rating (2.1) compared with the 2017 trial (2.6) (Table 1). Scores from two trials were significantly correlated $\left(\mathrm{R}^{2}=0.49\right.$, Table 2$)$. Heritability of BYD resistance ranged from 0.3 for 2016 trial to 0.8 for 2017 trial (Table 1).

TBIA score of parents and their derived DH lines. The virus status in the plants was assessed by TBIA. The average TBIA scores of the BYD sensitive parent H-120 were 2 and 2.5 in 2016 and 2017 trials, respectively, while XuBYDV showed very good resistance to BYD with an average TBIA score of 0.5 in both trials. TBIA scores of the DH population in the two trials showed normal distributions with a slight skewness toward greater susceptibility (Fig. 1B). The TBIA score of the DH population ranged from 0 to 3 in both trials with an average of 1.9 in the 2016 trial and 2.1 in the 2017 trial (Table 1; Fig. 1B). TBIA severity was significantly correlated between the trials and positively correlated with symptom severity scores (Table 2).
QTL for BYD symptom score. One major QTL ( $Q b y d v-S S-7 A)$ for BYD resistance was identified from both trials, with LOD values of 3.64 and 12.21, respectively, for the 2016 and 2017 trials. The QTL explained 8.9 and $25.5 \%$ of the phenotypic variation in two trials, respectively, and was located on the long arm of chromosome 7A with the closest marker of IWB31106 (Table 3). The resistant allele of the QTL was derived from the resistant parent XuBYDV. The 2017 trial showed more severe disease symptoms than the 2016 trial (Fig. 1A) and revealed an additional QTL for BYD resistance. This QTL was located on the long arm of chromosome 5A ( $Q b y d v-S S$ $5 A$ ), with the closest marker of IWA3704, and explained $7.1 \%$ of the phenotypic variation. The resistant allele for this QTL was also derived from the resistant parent XuBYDV. When data from the two trials were combined (CSS), the same two QTL were detected (Table 3; Fig. 2).

QTL for disease incidence (TBIA test). Two QTL were detected in the 2016 trial, one located on chromosome 7A (Qbydv-TS-7A) flanked by marker IWB31106 and the other on chromosome 6A $(Q b y d v-T S-6 A)$ flanked by marker IWA7802. They explained 11.2 and $7.6 \%$ of the phenotypic variation, respectively (Table 3 ), and the resistance allele of both QTL were derived from the resistant parent XuBYDV. For the 2017 trial, two QTL were identified on chromosome 7A $(Q b y d v-T S-7 A)$ and 5A $(Q b y d v-T S-5 A)$, flanked by marker IWB31106 and IWA3704, respectively (Fig. 2; Table 3). These QTL had the same locations as $Q b y d v-S S-7 A$ and $Q b y d v-S S-5 A$,

Table 2. Correlation coefficients of symptom severity and tissue blot immunoassay (TBIA) score in the population of XuBYDV/H-120 a

\begin{tabular}{lccc}
\hline Trial & $\begin{array}{c}\text { Symptom score } \\
\mathbf{2 0 1 6}\end{array}$ & $\begin{array}{c}\text { Symptom score } \\
\mathbf{2 0 1 7}\end{array}$ & $\begin{array}{c}\text { TBIA score } \\
\mathbf{2 0 1 6}\end{array}$ \\
\hline $\begin{array}{l}\text { Symptom score } \\
2017\end{array}$ & $0.49^{* *}$ & & \\
TBIA score 2016 & $0.51^{* *}$ & $0.52^{* *}$ & \\
TBIA score 2017 & $0.50^{* *}$ & $0.60^{* *}$ & $0.60^{* *}$ \\
\hline
\end{tabular}

a ** Indicate significant levels of $P<0.01$

Table 1. Barley yellow dwarf virus (BYDV) symptom severity and disease incidence of the two parents XuBYDV and H-120 and their derived DH population

\begin{tabular}{|c|c|c|c|c|c|c|c|}
\hline \multirow[b]{2}{*}{ Traits } & \multirow[b]{2}{*}{ Trials } & \multicolumn{2}{|c|}{ Mean of parents } & \multicolumn{4}{|c|}{ DH lines } \\
\hline & & XuBYDV & H-120 & Minimum & Maximum & Mean & $h^{2}$ \\
\hline \multirow{2}{*}{ Symptom severity (0-5 scale) } & 2016 & 1.0 & 3.0 & 0 & 4.0 & 2.1 & 0.3 \\
\hline & 2017 & 1.0 & 3.5 & 0 & 5.0 & 2.6 & 0.8 \\
\hline \multirow[t]{2}{*}{ TBIA score $(0-3$ scale $)$} & 2016 & 0.5 & 2.0 & 0 & 3.0 & 1.9 & 0.5 \\
\hline & 2017 & 0.5 & 2.5 & 0 & 3.0 & 2.1 & 0.8 \\
\hline
\end{tabular}

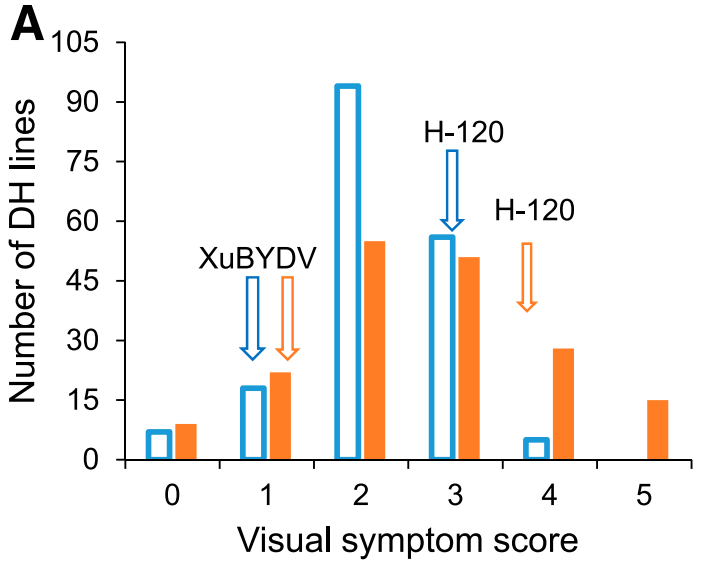

B

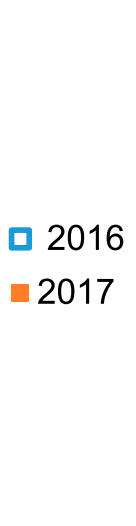

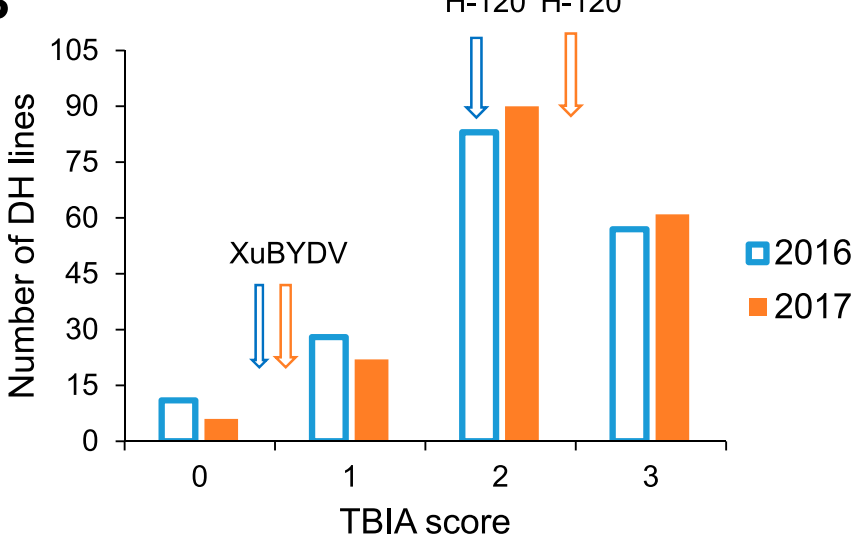

Fig. 1. Frequency distribution of barley yellow dwarf symptom scores (A) and tissue blot immunoassay (TBIA) scores (B) in 2016 and 2017 trials identified in the DH population of $\mathrm{XuBYDV/H-120.}$. Arrows indicate the value of parents. 
respectively. When the data from two trials were combined (CTS), the same three QTL in chromosome 7A, 5A, and 6A were detected (Table 3).

\section{Discussion}

Accurate phenotyping is crucial for robustly detecting and quantifying the effects of QTL (Zhou 2011). Our previous study revealed that visual BYD symptoms were not evident in most susceptible plants until head emergence (Choudhury et al. 2018). Further, the evaluation of BYDV stress is further complicated by variability in the spread of aphids and environmental impacts on the efficiency of transmission of virus from aphids to plants. Consequently, to increase phenotyping accuracy we used the combination of visual symptom and TBIA scores to assess BYDV symptoms in the DH population and parental lines across 2 years of field trials. A strong positive correlation was observed between both scoring methods and across years (Table 2).

The leaf symptoms found in BYDV-infected plants are commonly used to select BYD resistance in cereal crops (Choudhury et al. 2018;
Kosova et al. 2008). The BYDV infection protocol used in our study allowed clear and reliable differentiation of genotypes that would have been difficult to achieve under natural infection. Most of the DH lines showed symptoms of BYDV infection, which was confirmed by the detection of the virus using TBIA. The major allele controlling BYDV resistance was located on chromosome 7A with the peak marker IWB31106 showing highly significant association with resistance in both years for both traits (symptom score and TBIA score). No QTL for BYD resistance has previously been reported on 7A. In general, chromosome group 7 may be of special interest for BYD resistance and tolerance because in both Thinopyrum intermedium and wheat (Triticum aestivum), tolerance has been assigned to this chromosome group (Larkin et al. 1995; Singh et al. 1993).

A QTL on chromosome $5 \mathrm{~A}$ at around $230 \mathrm{cM}$ was detected for both symptom score and TBIA score in the 2017 trial. Previously, a QTL for yellowing caused by BYDV on chromosome 5A was identified in the Opata $\times$ Synthetic population, although it was located at a different position (Ayala et al. 2002) based on the position of the nearest markers to the QTL on the consensus map. In addition, a

Table 3. QTL for barley yellow dwarf symptom score (SS) and tissue blot immunoassay (TBIA) score (TS) identified in the DH population of XuBYDV/H-120

\begin{tabular}{|c|c|c|c|c|c|c|c|}
\hline Trial & QTL & Chromosome & Genetic map position & LOD score & $\mathbf{R}^{2}(\%)$ & 2-LOD interval & Nearest marker \\
\hline Symptom score 2016 & $Q T L-S S-7 A$ & $7 \mathrm{~A}$ & 156.6 & 3.64 & 8.9 & $155.6-161.1$ & IWB31106 \\
\hline \multirow[t]{2}{*}{ Symptom score 2017} & $Q T L-S S-7 A$ & $7 \mathrm{~A}$ & 156.6 & 12.21 & 25.5 & $155.6-161.1$ & IWB31106 \\
\hline & $Q T L-S S-5 A$ & $5 \mathrm{~A}$ & 235.5 & 3.82 & 7.1 & $231.1-236.1$ & IWA3704 \\
\hline \multirow[t]{2}{*}{ Combined symptom score } & $Q T L-S S-7 A$ & $7 \mathrm{~A}$ & 156.6 & 11.47 & 24.2 & $155.6-161.1$ & IWB31106 \\
\hline & $Q T L-S S-5 A$ & $5 \mathrm{~A}$ & 235.5 & 3.61 & 6.9 & $231.1-236.1$ & IWA3704 \\
\hline \multirow[t]{2}{*}{ TBIA score 2016} & $Q T L-T S-7 A$ & $7 \mathrm{~A}$ & 156.6 & 5.14 & 11.2 & $155.6-161.1$ & IWA31106 \\
\hline & $Q T L-T S-6 A$ & $6 \mathrm{~A}$ & 5.56 & 3.56 & 7.6 & $3.9-10.0$ & IWA7802 \\
\hline \multirow[t]{2}{*}{ TBIA score 2017} & $Q T L-T S-7 A$ & $7 \mathrm{~A}$ & 156.6 & 6.8 & 15.1 & $155.6-161.1$ & IWA31106 \\
\hline & $Q T L-T S-5 A$ & $5 \mathrm{~A}$ & 235.5 & 3.20 & 6.8 & $231.1-236.1$ & IWA3704 \\
\hline \multirow[t]{3}{*}{ Combined TBIA score } & $Q T L-C S S-7 A$ & $7 \mathrm{~A}$ & 156.6 & 7.16 & 16.7 & $155.6-161.1$ & IWA31106 \\
\hline & $Q T L-C T S-5 A$ & $5 \mathrm{~A}$ & 235.5 & 2.97 & 6.1 & $231.1-236.1$ & IWA3704 \\
\hline & $Q T L-C T S-6 A$ & $6 \mathrm{~A}$ & 5.56 & 3.41 & 7 & $3.9-10.0$ & IWA7802 \\
\hline
\end{tabular}

$5 \mathrm{~A}$

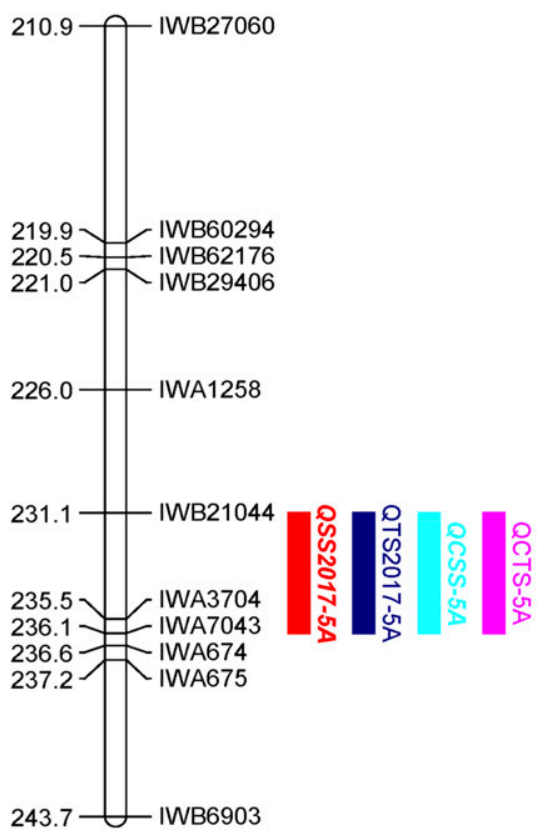

$6 \mathrm{~A}$

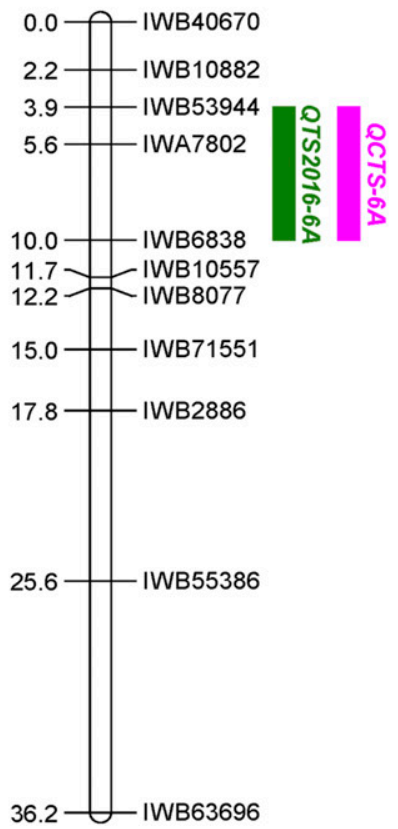

7A

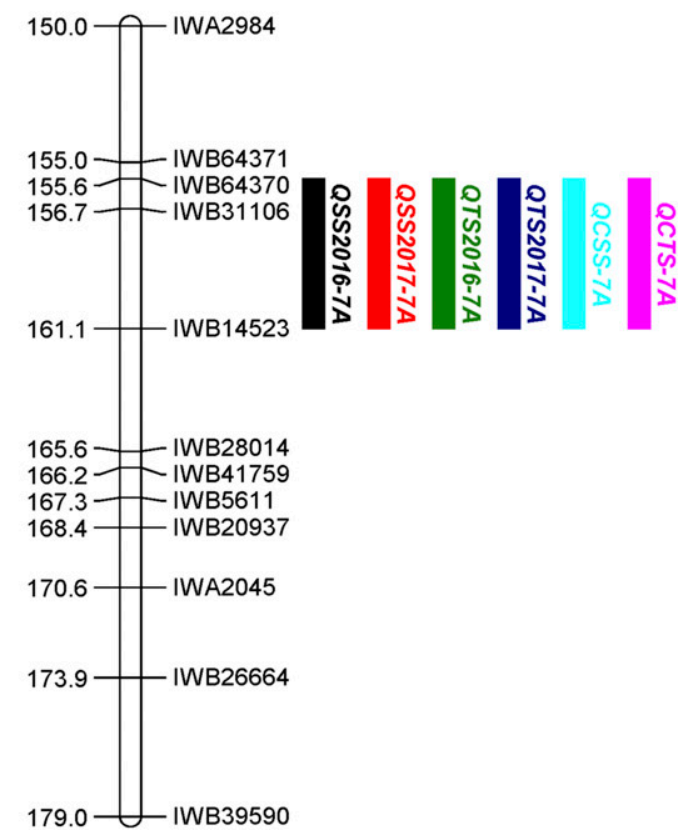

Fig. 2. QTL for barley yellow dwarf resistance identified from DH population originated from the cross between XuBYDV and H-120. Only selected markers are shown; QSS20167A: QTL for symptom score 2016, QSS2017-5A, -7A: QTL for symptom score 2017, QTS2016-6A, -7A: QTL for tissue blot immunoassay (TBIA) score 2016, QTS2017-5A, -7A: QTL for TBIA score 2017, QCSS-5A, -7A: QTL for combined symptom score, QCTS-5A, -6A, -7A: QTL combined TBIA score. 
QTL on chromosome 6A around $5 \mathrm{cM}$ was identified in the DH population for TBIA score in the 2016 trial. This QTL is also found to be at a different position to that identified for leaf yellowing and biomass reduction in the Opata $\times$ Synthetic populations (Ayala et al. 2002) based on the position of the nearest markers to the QTL on the consensus map. The 6A QTL identified for TBIA score was not significant for the disease symptom in the field $(\mathrm{LOD}=1.82$ ), most likely because some BYDV infected lines by TBIA did not show leaf symptoms, i.e., tolerance to virus infection. For example, two DH lines (DH212 and DH236) had maximum score (3) of TBIA but showed moderate tolerance (1.5) in the field in both field trials.

Assessing BYD resistance using phenotypic selection can be difficult due to the complex interactions among host genes, viruses, vectors, and environmental conditions (Jin et al. 1998). The effect of environmental factors on the efficiency of plant virus transmission makes it extremely difficult to predict the complex interaction of plant-virus-vector (Blanc and Michalakis 2016). The evaluation of BYD resistance in different year trials allowed the individual phenotypic evaluation of DH population. The relatively higher heritabilities (Table 1) in both symptom score and TBIA score in the 2017 trial proved to be a prerequisite for successful identification of minor QTL which were not identified in the 2016 trial, which had less severe infection and lower heritabilities. After screening the parents and DH population with a $B d v 2$-specific marker, BYAgi (Stoutjesdijk et al. 2001), it was confirmed that the population did not contain the $B d v 2$ gene on 7DL. The effectiveness and additivity of the three new QTL was confirmed in DH lines with various combinations of the identified QTL (Fig. 3). DH270 had all three QTL and showed very high BYD resistance.

We conclude the three new QTL on chromosomes 5A, 6A, and 7A materially contribute to BYD resistance in wheat. They appear to be additive in effect, since their combination in specific DH lines resulted in high levels of BYD resistance (e.g., Fig. 3). The markers identified can be used in marker-assisted selection to pyramid these resistance genes to develop genotypes with better resistance to BYDV infection.

\begin{tabular}{|c|c|c|c|c|c|}
\hline \multicolumn{3}{|c|}{$\mathrm{DH}$ line } & \multicolumn{2}{|c|}{ DH270 DH314 } & DH015 \\
\hline \multicolumn{3}{|c|}{2016 symptom score } & $\mathbf{0}$ & 3 & 1 \\
\hline \multicolumn{3}{|c|}{2017 symptom score } & $\mathbf{0}$ & 2 & 1 \\
\hline \multirow{2}{*}{\multicolumn{3}{|c|}{$\begin{array}{l}2016 \text { TBIA score } \\
2017 \text { TBIA score }\end{array}$}} & $\mathbf{o}$ & 3 & 0.5 \\
\hline & & & 0.5 & 3 & $\mathbf{0}$ \\
\hline Chromosome & Position & Marker ID & & & \\
\hline $5 A$ & 220.47 & IWB62176 & a & b & a \\
\hline $5 A$ & 221.02 & IWB29406 & a & b & a \\
\hline $5 \mathrm{~A}$ & 226.04 & IWA1258 & a & b & a \\
\hline $5 \mathrm{~A}$ & 231.05 & IWB21044 & a & b & a \\
\hline 5A & 235.51 & IWA3704 & $\mathbf{a}$ & b & $\mathbf{a}$ \\
\hline 5A & 236.07 & IWA7043 & a & b & a \\
\hline $5 \mathrm{~A}$ & 236.62 & IWA677 & a & b & a \\
\hline $6 \mathrm{~A}$ & 0.00 & IWB40670 & $\mathbf{a}$ & b & a \\
\hline $6 A$ & 2.22 & IWB10882 & a & b & a \\
\hline $6 \mathrm{~A}$ & 3.89 & IWB53944 & a & b & a \\
\hline 6A & 5.56 & IWA7802 & $\mathbf{a}$ & b & $\mathbf{a}$ \\
\hline $6 \mathrm{~A}$ & 10.01 & IWB6838 & a & b & a \\
\hline $6 A$ & 11.68 & IWB10557 & a & b & a \\
\hline $6 \mathrm{~A}$ & 12.24 & IWB8077 & a & b & a \\
\hline $7 A$ & 150.00 & IWA2984 & a & a & b \\
\hline $7 \mathrm{~A}$ & 155.02 & IWB64371 & $\mathbf{a}$ & a & b \\
\hline $7 A$ & 155.57 & INB64370 & a & a & b \\
\hline 7A & 156.68 & IWB31106 & $\mathbf{a}$ & $\mathbf{a}$ & b \\
\hline $7 A$ & 161.24 & INB14523 & a & $\vec{a}$ & b \\
\hline $7 \mathrm{~A}$ & 165.60 & IWB28014 & a & a & b \\
\hline $7 \mathrm{~A}$ & 166.15 & IWB41759 & a & a & b \\
\hline $7 \mathrm{~A}$ & 167.26 & INB5611 & $a$ & a & b \\
\hline /A & 168.31 & IVVBZUY3' & $a$ & a & D \\
\hline $7 A$ & 173.94 & IWB26664 & $a$ & a & b \\
\hline $7 \mathrm{~A}$ & 178.95 & INB39590 & a & a & b \\
\hline & a & Resistance & & & \\
\hline & b & Susceptible & ele & & \\
\hline
\end{tabular}

Fig. 3. Barley yellow dwarf resistance of selected $\mathrm{DH}$ lines with different combinations among the three QTL on $5 \mathrm{~A}, 6 \mathrm{~A}$, and $7 \mathrm{~A}$. For symptom scores, $0=$ no symptoms; $5=$ almost all ( $>60 \%$ ) of leaves are affected. For tissue blot immunoassay (TBIA) scores: Score 0 represented no virus; score 3 represented higher number of vascular bundles $(>50 \%)$ infected, strongly stained vascular bundles.

\section{Literature Cited}

Ayala, L., Henry, M., Gonzalez-de-Leon, D., Van Ginkel, M., Mujeeb-Kazi, A., Keller, B., and Khairallah, M. 2001. A diagnostic molecular marker allowing the study of Th. intermedium-derived resistance to BYDV in bread wheat segregating populations. Theor. Appl. Genet. 102:942-949.

Ayala, L., Henry, M., Van Ginkel, M., Singh, R., Keller, B., and Khairallah, M. 2002. Identification of QTLs for BYDV tolerance in bread wheat. Euphytica 128:249-259.

Balaji, B., Bucholtz, D. B., and Anderson, J. M. 2003. Barley yellow dwarf virus and Cereal yellow dwarf virus Quantification by Real-Time Polymerase Chain Reaction in Resistant and Susceptible Plants. Virology 93:1386-1392.

Baltenberger, D., Ohm, H., and Foster, J. 1987. Reactions of Oat, Barley, and Wheat to Infection with Barley Yellow Dwarf Virus Isolates 1. Crop Sci. 27:195-198.

Barbosa-Neto, J. F., Siripoonwiwat, W., O'donoughue, L. S., Gray, S. M., Smith, D. M., Kolb, F. L., Gourmet, C., Brown, C. M., and Sorrells, M. E. 2000. Chromosomal regions associated with barley yellow dwarf virus resistance in oat. Euphytica 114:67-76.

Blanc, S., and Michalakis, Y. 2016. Manipulation of hosts and vectors by plant viruses and impact of the environment. Curr. Opin. Insect Sci. 16:36-43.

Choudhury, S., Al-shammari, D., Hu, H., Meinke, H., Westmore, G., Birchall, C., Larkin, P., and Zhou, M. 2018. A screening method to detect BYDV-PAV resistance in cereals under glasshouse conditions. Plant Pathol. 67:1987-1996.

Cisar, G., Brown, C., and Jedlinski, H. 1982. Diallel analyses for tolerance in winter wheat to the barley yellow dwarf virus 1. Crop Sci. 22:328-333.

Comeau, A. 1992. Interactions between barley yellow dwarf virus, aphids, plants and fungal diseases: an ecological model. Proceedings of the Barley yellow dwarf in West Asia and North Africa: Proceedings of a workshop organized by the ICARDA and IDRC held in Rabat, Morocco, 19-21 November 1989. A. Comeau and K. M. Makkouk, eds. ICARDA, Aleppo, Syria.

Cooper, J., and Jones, A. 1983. Responses of plants to viruses: Proposals for the use of terms. Phytopathology 73:127-128.

Griesbach, J., Falk, B., and Valverde, R. 1990. Incidence of barley yellow dwarf viruses in California cereals. Plant Dis. 74:111-114.

Halbert, S., and Voegtlin, D. 1995. Biology and taxonomy of vectors of barley yellow dwarf viruses. Pages 217-258 in: Barley Yellow Dwarf: 40 Years of Progress. C. J. D'Arcy and P. A. Burnett, eds. APS Press, St. Paul, MN.

Hewer, A., Becker, A., and Van Bel, A. J. 2011. An aphid's Odyssey-the cortical quest for the vascular bundle. J. Exp. Biol. 214:3868-3879.

Hoffman, T., and Kolb, F. 1997. Effects of barley yellow dwarf virus on root and shoot growth of winter wheat seedlings grown in aeroponic culture. Plant Dis. 81:497-500.

Huth, W. 1999. Tissue-print immunoassay: A rapid and reliable method for routinely detecting gramineae viruses. Plant Res. Dev. 49:7-19.

Huth, W. 2000. Viruses of Gramineae in Germany-a short overview/Viren der Gramineen in Deutschland-ein kurzer Überblick. Zeitschrift für Pflanzenkrankheiten und Pflanzenschutz. J. Plant Dis. Prot. 1:406-414.

Jiménez-Martinez, E., and Bosque-Pérez, N. 2004. Variation in barley yellow dwarf virus transmission efficiency by Rhopalosiphum padi (Homoptera: Aphididae) after acquisition from transgenic and nontransformed wheat genotypes. J. Econ. Entomol. 97:1790-1796.

Jin, H., Domier, L. L., Kolb, F. L., and Brown, C. M. 1998. Identification of quantitative loci for tolerance to barley yellow dwarf virus in oat. Phytopathology 88:410-415.

Kaddachi, I., Souiden, Y., Achouri, D., and Chéour, F. 2014. Barley yellow dwarf virus (BYDV): characteristics, hosts, vectors, disease symptoms and diagnosis. Int. J. Phytopathol. 3:155-160.

Kearsey, M., and Farquhar, A. 1998. QTL analysis in plants; where are we now? Heredity 80:137-142.

Kosová, K., Chrpova, J., and Sip, V. 2008. Recent advances in breeding of cereals for resistance to barley yellow dwarf virus. Czech J. Genet. Plant Breed. 44: $1-10$.

Larkin, P. J., Banks, P. M., Lagudah, E. S., Apples, R., Xiao, C., Zhiyong, X., Ohm, H. W., and Mclntosh, R. A. 1995. Disomic Thinopyrum intermedium addition lines in wheat with barley yellow dwarf virus resistance and with rust resistances. Genome 38:385-394

Lin, N. S., Hsu, Y. H., and Hsu, H. T. 1990. Immunological detection of plant viruses and a mycoplasmalike organism by direct tissue blotting on nitrocellulose membranes. Phytopathology 80:824-828.

Makkouk, K., and Comeau, A. 1994. Evaluation of various methods for the detection of barley yellow dwarf virus by the tissue-blot immunoassay and its use for virus detection in cereals inoculated at different growth stages. Eur. J. Plant Pathol. 100:71-80.

McKenzie, R., Burnett, P., Gill, C., Comeau, A., and Brown, P. 1985. Inheritance of tolerance to barley yellow dwarf virus in oats. Euphytica 34:681-687.

Miller, W. A., and Rasochová, L. 1997. Barley yellow dwarf viruses. Annu. Rev. Phytopathol. 35:167-190.

Miller, W. A., Waterhouse, P. M., and Gerlach, W. L. 1988. Sequence and organization of barley yellow dwarf virus genomic RNA. Nucleic Acids Res. 16:6097-6111.

Money, D., Gardner, K., Migicovsky, Z., Schwaninger, H., Zhong, G. Y., and Myles, S. 2015. LinkImpute: Fast and accurate genotype imputation for nonmodel organisms. G3. Genes Genom. Genet. 5:2383-2390. 
Nagy, A. A., Sharaf, A. N., Soliman, M. H., Shalaby, A. A., and Youssef, S. A. 2007. Molecular characterization of barley yellow dwarf virus coat protein gene in wheat and aphids. Arab J. Biotechnol. 10:207-218.

Nyquist, W. E., and Baker, R. 1991. Estimation of heritability and prediction of selection response in plant populations. Crit. Rev. Plant Sci. 10: 235-322.

Ooijen, J., and Kyazma, B. 2009. MapQTL 6.0, software for the mapping of quantitative trait loci in experimental populations of dihaploid species. Wageningen, Netherlands.

Ordon, F., Friedt, W., Scheurer, K., Pellio, B., Werner, K., Neuhaus, G., Huth, W., Habekuss, A., and Graner, A. 2004. Molecular markers in breeding for virus resistance in barley. J. Appl. Genet. 45:145-160.

Qualset, C. 1992. Developing host plant resistance to barley yellow dwarf virus: An effective control strategy. Barley Yellow Dwarf in West Asia and North Africa, 115-138. ICARDA, Aleppo, Syria.

Riedell, W. E., Kieckhefer, R. W., Langham, M. A., and Hesler, L. S. 2003. Root and Shoot Responses to Bird Cherry-Oat Aphids and in Spring Wheat. Crop Sci. 43:1380-1386.

Schaller, C. 1984. The genetics of resistance to barley yellow dwarf virus in barley. Proceedings of the Barley yellow dwarf. A proceedings of the workshop. CIMMYT, Mexico, 93-99.

Schwinghamer, M. W., Schilg, M. A., Walsh, J. A., Bambach, R. W., Cossu, R. M., Bambridge, J. M., Hind-Lanoiselet, T. L., Mccorkell, B. E., and Cross, P. 2014. Turnip mosaic virus: Potential for crop losses in the grain belt of New South Wales, Australia. Australas. Plant Pathol. 43:663-678.

Singh, R. P., Burnett, P. A., Albarran, M., and Rajaram, S. 1993. Bdv1: A gene for tolerance to barley yellow dwarf virus in bread wheats. Crop Sci. 33:231-234.

Smith, P., and Sward, R. 1982. Crop loss assessment studies on the effects of barley yellow dwarf virus in wheat in Victoria. Aust. J. Agric. Res. 33:179-185.
Stoutjesdijk, P., Kammholz, S., Kleven, S., Matsay, S., Banks, P., and Larkin, P. 2001. PCR-based molecular marker for the Bdv2 Thinopyrum intermedium source of barley yellow dwarf virus resistance in wheat. Aust. J. Agric. Res. 52:1383-1388.

Tola, J., and Kronstad, W. 1984. The genetics of resistance to barley yellow dwarf virus in wheat. Proceedings of the Barley Yellow Dwarf Workshop, Mexico, DF (Mexico), 6-8 Dec 1983, CIMMYT.

Toojinda, T., Broers, L. H., Chen, X. M., Hayes, P. M., Kleinhofs, A., Korte, J., Kudrna, D., Leung, H., Line, R. F., Powell, W., and Ramsay, L. 2000. Mapping quantitative and qualitative disease resistance genes in a doubled haploid population of barley (Hordeum vulgare). Theor. Appl. Genet. 101: 580-589.

Veškrna, O., Chrpová, J., Šíp, V., Sedláček, T., and Horčička, P. 2009. Reaction of wheat varieties to infection with barley yellow dwarf virus and prospects for resistance breeding. Czech J. Genet. Plant Breed. 45:45-56.

Voorrips, R. 2002. MapChart: Software for the graphical presentation of linkage maps and QTLs. J. Hered. 93:77-78.

Wang, S., Wong, D., Forrest, K., Allen, A., Chao, S., Huang, B. E., Maccaferri, M., Salvi, S., Milner, S. G., and Cattivelli, L. 2014. Characterization of polyploid wheat genomic diversity using a high-density 90000 single nucleotide polymorphism array. Plant Biotechnol. J. 12:787-796.

Zhou, M. 2011. Accurate phenotyping reveals better QTL for waterlogging tolerance in barley. Plant Breed. 130:203-208.

Zhou, M., Larkin, P., Schwinghamer, M., Coutts, B., Birchall, C., Johnson, P., Westmore, G., and Davey, B. 2015. Studies on barley yellow dwarf virus (BYDV) in wheat. Pages 737-740 in: Proceedings of the 17th Australian Agronomy Conference. T. Acuña, M. Harrison, C. Moeller, and D. Parsons, eds. Australian Society of Agronomy, Warragul, Australia. ([Accessed 2018], http://agronomyaustraliaproceedings.org/images/sampledata/ ASA17ConferenceProceedings2015.pdf 